Referencia al citar este artículo:

Martínez, E. (2014). La pedagogía de Santo Tomás ante una educación sin maestros. En: Revista TEMAS, $3(8), 29-37$.

\title{
La pedagogía de Santo Tomás ante una educación sin maestros ${ }^{1}$
}

Enrique Martínez ${ }^{2}$

Recibido: $28 / 08 / 2014$

Aceptado: 17/09/2014

\section{Resumen}

La acedia como la actividad del hombre que deprime, en donde nada de lo que hace le agrada, es el efecto más notorio de la despersonalización. Para examinar si en nuestra sociedad se da esta acedia este artículo dirige su atención a un ámbito nuclear de la vida humana: la educación. ¿En qué momento la vocación docente se traslada a simple trabajo asalariado? ¿Por qué esforzarse para que los estudiantes aprendan? Estas preguntas son objeto de este artículo y cuyas respuestas serán analizadas desde el pensamiento de Santo Tomas de Aquino. En este sentido, el artículo se divide en dos partes; por un lado, en la caracterización de la acedia y del rol de esta en la formación del estudiante, y de otro, en el papel que juega el profesor una vez se ha despersonalizado. Concluye que la falta de sentido esta por detrás de cualquier estrategia pedagógica que fomente la educación y, por tanto, es menester volver a casa (personalizar) para ser conscientes de la vocación recibida y así, educar.

\section{Palabras clave:}

Educación, Despersonalización, Santo Tomás de Aquino, Francisco Canals, Vocación.

\section{St. Thomas pedagogy in light of education without teachers}

\begin{abstract}
Acedia is understood as the activity of a man in state of depression, as he does not like anything he is doing; it is the more notorious effect of depersonalization. In order to examine if, in our society, we can observe this acedia, this article focuses its attention towards a nuclear area of human life: education. When does the teaching vocation simply moved to a simple paid work? Why should we make efforts for students to learn? These questions are the object of this article and the answers will be analyzed based on the thought of St. Thomas Aquinas. In this regard, the article is divided in two parts; on the one hand, it investigates the characterization of acedia and its role in the student's training and, on the other hand, it researches on the role of the teacher once he/she was depersonalized. The paper concludes that the lack of meaning is behind any pedagogical strategy that promotes education and, therefore, it is necessary to return home (personalize) in order to be conscious of the vocation received and thus, educate.
\end{abstract}

\section{Keywords:}

Depersonalization, Education, St. Thomas Aquinas, Francisco Canals, Vocation.

\footnotetext{
1 Artículo de reflexión presentado como ponencia en la Universidad Santo Tomás Seccional Bucaramanga, Colombia (28 de febrero de 2014).
}

2 Doctor Enrique Martínez, Universitat Abat Oliba - CEU Barcelona, España. E-mail: emartinez@uao.es 


\section{INTRODUCCIÓN}

"El hombre a quien nadie miró". Estas palabras del maestro Francisco Canals, sintetizan la naturaleza de la despersonalización que padece hoy nuestra sociedad, objeto de reflexión en este escrito. Podría escribirse hoy, decía Canals, la biografía novelesca de alguien "reiteradamente fotografiado, radiografiado, sometido a análisis clínicos, y test psicológicos, y cuyos datos podrían estar archivados en abundantes ficheros y memorias electrónicas", la biografía de un hombre que "en su trágica soledad, perdido en lo público y sumergido en la socialización impersonal de pretendidas 'relaciones humanas', podría ser caracterizado con el título de el hombre a quien nadie miró" (Canals, 1976, p. 112-113).

Todo hombre, por el contrario, exige ser mirado como alguien y no como algo. Es lo que corresponde a la dignidad de quien subsiste en la naturaleza racional, por la que el hombre tiene conciencia de sí y dominio de sus actos; es lo que corresponde a la dignidad de quien tiene un ser distinto e incomunicable, "personal e intransferible"; es lo que corresponde a la dignidad de quien es "lo más perfecto de toda la naturaleza", esto es, la persona (Aquino, Summa Theologiae I, q.29, a.3 in c.)

Que el hombre tenga esta dignidad ya era en cierto modo percibido por los antiguos. El término griego "prósopon", "aquello que está ante los ojos" (Chantraine, 1984, p. 942), comenzó significando "rostro humano"; luego se añadieron las acepciones de "aspecto", "presencia", "máscara" o "personaje"; y finalmente llegó a referirse al individuo de naturaleza racional, a la persona (Martínez, 2010, p. 139). $Y$ es que por el rostro cada hombre es reconocido como distinto de los otros y mirado como alguien. No es de extrañar, pues, que la despersonalización sea caracterizada como la ausencia de esa mirada que reconoce a alguien en su individualidad.

Ahora bien, ¿se da esta despersonalización en nuestra sociedad? Podemos confirmar el diagnóstico del profesor Canals constatando sus efectos. ¿Cuáles son estos? Quien no experimenta ser mirado, conocido, amado, acaba reconociéndose en una profunda soledad, a pesar de las numerosas relaciones sociales en las que viva inmerso. $Y$ esta soledad provoca la tristeza cotidiana por un bien como es la propia vida, o la tristeza por la compañía de los otros, cuya mirada se vuelve entonces amenazadora. Esta tristeza es lo que antiguamente se denominaba "acedia" y que Santo Tomás de Aquino definía así:

La acedia es cierta tristeza que apesadumbra, es decir, que de tal manera deprime el ánimo del hombre, que nada de lo que hace le agrada, igual que se vuelven frías las cosas por la acción corrosiva del ácido" (Aquino, Summa Theologiae II-II, q.35, a.1 in c).

La acedia es, así, el efecto más notorio de la despersonalización.

\section{UNA SOCIEDAD DESPERSONALIZA- DA}

Para examinar si en nuestra sociedad se da esta acedia dirigiremos nuestra atención a un ámbito nuclear de la vida humana: la educación. Veamos si se da en ella una primera manifestación de la acedia, que consiste en huir del bien que le causa tristeza, ya que "nadie puede permanecer largo tiempo en la tristeza", explica Aristóteles (Ética Nicomáquea, VIII, c.5, 1157b15) ¿Cómo huye? Perdiendo la esperanza de alcanzarlo. Cuando el fin deja de serlo, y se juzga como algo ilusorio, entonces toda la actividad se resiente y pierde sentido: ¿Por qué seguir actuando? Eso es lo que le sucede, por ejemplo, al que ya no siente el gozo de educar, y se ve embargado por una pesada tristeza: "¿Por qué seguir educando?", 
se pregunta. Reniega entonces del término "vocación", pues le recuerda el día en que entendía su actividad como algo bueno y posible. "No, educar es una utopía", se repite a sí mismo, y trata de huir de su tristeza sustituyendo la propia vocación docente por un trabajo asalariado. Y qué decir del alumno que se pregunta en su tristeza "¿por qué seguir estudiando?" Se responde cabizbajo que eso es para otros, y que mejor trabajar para poder divertirse los fines de semana.

La pérdida de sentido del fin afecta también a los medios. Si no se sabe por qué hay que educar, entonces ¿Por qué hay que esforzarse?, ¿por qué hay que exigir a los alumnos? Si consideramos esto con atención, comprenderemos cuál es la razón de la actual aversión a cualquier forma de exigencia en la educación; no se trata de una estrategia pedagógica para motivar un aprendizaje más activo, ni siquiera un planteamiento ideológico que busque fomentar la libertad frente a pedagogías tildadas de autoritarias; lo que de verdad se esconde tras esas actitudes es la falta de sentido.

Y si no hay que esforzarse para estudiar, ¿qué se hace entonces en la escuela? Algunos se dejarán arrastrar por la pereza, pero no aquella que se puede tener un lunes cuando suena el despertador, sino la pereza del que ha arrojado la toalla, la pereza del que siente una pesada losa que paraliza su voluntad. Esta pereza, sin embargo, adquiere en ocasiones una curiosa modalidad que Canals denominó "pereza activa" (Canals, 2004, p.1), esto es, formas activas de distraerse para huir del vacío interior. Santo Tomás (Summa Theologiae II-II, q.35, a.4 ad 3) enumera cuatro: Primero está la curiosidad, y así se enseña en la escuela un variadísimo pero superficial e inconexo conjunto de conocimientos; los alumnos se dedican más a navegar por internet que a leer un libro en profundidad; y las aulas de los niveles superiores parecen una prolongación de la etapa infantil. La segunda forma de "activismo" es la verbosidad o vana palabrería, de aquí que se dan en la escuela reuniones interminables para discutir sobre nuevas metodologías educativas, y se sermonea una y otra vez a los niños sobre valores abstractos, mientras ellos son incapaces de callar en el aula. En tercer lugar, se refiere lo que el Aquinate denomina inquietud corporal, que es típica de los alumnos dedicados sin descanso a actividades extraescolares, e incapaces de mantenerse sentados en el aula. $Y$ finalmente, se encuentra la variabilidad de proyectos, que es típica de los maestros dedicados también sin descanso a redactar informes, diseñar actividades, rellenar formularios, elaborar presentaciones mediante las nuevas tecnologías, entre otros; esta forma de "pereza activa" es también reconocible en la renovación incesante de legislaciones educativas, al menos en España, desoyendo aquel sabio consejo de Aristóteles (Política, II, c.5) de no modificar frecuentemente las leyes, ni aun cuando sea para mejorarlas un poco.

Todo ello para huir del vacío interior del que no sabe qué hace en la escuela. Pero el análisis de Santo Tomás aún nos aporta una última luz, cuando explica que una de las maneras de huir de la acedia es atacando el mismo bien que causa la tristeza. ¿Y cómo se ataca un bien? Impugnándolo racionalmente, transmutando el bien en mal. Es lo propio del resentimiento en la moral que describió Max Scheler (1993). Los pedagogos califican entonces de totalitarios a quienes buscan educar en el bien o en la verdad, y se les responde como Pilato: "¿Y qué es la verdad?". Esos pedagogos reducen la educación una mera construcción que cada cual hace de su propio camino: "Caminante, no hay camino, se hace camino al andar", decía el poeta. O, en palabras del presidente del gobierno español: "La libertad os hará verdaderos", 
transmutando así la frase del Evangelio. Si Sheller hablaba del resentimiento en la moral, nosotros podríamos hablar hoy del resentimiento en la educación.

Por este resentimiento se reacciona con desprecio hacia aquellos maestros que exigen un esfuerzo o un buen comportamiento, hacia aquellos maestros que no renuncian a su autoridad. No, lo que hay que hacer es descender al mismo nivel que los alumnos. iPero qué error suprimir las tarimas en las aulas! Por lo mismo, se reacciona también con desprecio hacia aquellos alumnos estudiosos o disciplinados. No, lo que hay que hacer es igualar democráticamente las calificaciones, no se vaya a ofender a los alumnos que no son brillantes.

Por este resentimiento, en definitiva, el alumno deja de sentir la necesidad de maestros. Por el contrario, se cree capaz de construir con las propias fuerzas su propia educación, su propio camino, su propio destino... Se cree maestro de sí mismo. Pero ello no es sino fruto de su soledad, la del "alumno a quien nadie miró".

Y si esta acedia la reconocemos claramente en la vida educativa, que es alma de la vida social, podemos confirmar que nos encontramos en una sociedad en donde el hombre se experimenta "en su trágica soledad, perdido en lo público y sumergido en la socialización impersonal", como describe Canals (1976) la despersonalización actual.

Pero, ¿qué ha conducido a esta situación? Hemos visto que el resultado final de la despersonalización es la autosuficiencia; ahora bien, si lo consideramos con atención podremos reconocer que esta estaba en germen al inicio, y que es en realidad la causa misma de toda la crisis despersonalizadora. $Y$ esto es lo que quiero mostrar a continuación, en la segunda parte de esta reflexión.

\section{¿MAESTRO DE SÍ MISMO?}

Y volveré a dirigir la reflexión hacia la educación. Hay que comenzar preguntándose si alguien puede llamarse maestro de sí mismo. Lo responde Santo Tomás en el artículo segundo de la cuestión De Magistro: el hombre no puede ser maestro de sí mismo, pues le falta la ciencia previa que desea adquirir (De Veritate q.11, a.2). Por eso, todo hombre en su indigencia necesita un maestro a quien oír y que le guíe por los caminos de la ciencia, la virtud y la sabiduría: "Para que el hombre se perfeccione en la sabiduría -afirma el Aquinate en otro lugar- es necesario que escuche de buena gana, porque la sabiduría es en esto profunda cuando el hombre no se basta a sí mismo para contemplar" (Aquino, Sermo Puer lesu pars 3).

“El hombre no se basta a sí mismo": iQué gran verdad! Y pretender lo contrario es lo propio de la soberbia, por la que alguien aspira a algo que está por encima de sus posibilidades. Es lo que le sucede al que se cree maestro de sí mismo. La soberbia, explica el Aquinate (Summa Theologiae II-II, q.162, a.7), es el principio de todos los pecados, y además es el último en desaparecer. Por eso no extraña que lo último que se manifiesta en la crisis educativa es lo que la ha originado: la soberbia del que se cree maestro de sí mismo.

Esta soberbia, sin embargo, no se da primero en la escuela, sino en el seno mismo de la familia. Hemos examinado hasta ahora la crisis educativa en la escuela, pues es más fácil considerarla fuera de la intimidad familiar. Pero ahora hay que acudir al lugar en donde se da la educación más íntima y fecunda: la familia, "útero espiritual" en palabras del Aquinate (Summa Theologiae II-II). En efecto, la educación viene a completar de un modo natural a la procreación y la crianza, y de ahí que pueda ser calificada como una "segunda generación" (Millán- 
Puelles, 1989, p. 32). Por eso es evidente que los primeros educadores son los padres. Además, la educación paterna se caracteriza por la profundidad e intimidad que requiere el más importante crecimiento en la vida personal, condiciones que no se dan ni en la escuela, ni en la vida social iQué difícil suplir en la escuela lo que no se ha dado en la familia! Por esta razón, se debe afirmar que esta educación paterna no sólo es la primera, sino la principal, y que toda otra educación posterior será secundaria y subsidiaria. De ahí que el término "padre" pueda ser usado secundariamente para los maestros y los gobernantes:

El padre -explica Santo Tomás- es el principio de la generación, crianza, educación y de todo lo relativo a la perfección de nuestra vida humana; en cambio, la persona constituida en dignidad es, por así decirlo, principio de gobierno sólo en algunas cosas, como el príncipe en asuntos civiles, el jefe del ejército en los militares, el maestro en la enseñanza, y así en todo lo demás. De ahí el que a tales personas se las llame también padres por la semejanza del cargo que desempeñan ${ }^{3}$.

De esta principalidad de los padres en la educación de los hijos se derivan varias importantes consecuencias, que ahora sólo voy a mencionar. En primer lugar, los hijos tienen derecho, tanto en la generación como en la educación, a un padre y una madre, a un matrimonio unido por un amor fiel e indisoluble. En segundo lugar, los padres tienen derecho a que la educación que dan a sus hijos sea protegida por las leyes, no permitiéndose la intromisión de otras instancias en el

3 Pater est principium et generationis et educationis et disciplinae, et omnium quae ad perfectionem humanae vitae pertinent. Persona autem in dignitate constituta est sicut principium gubernationis respectu aliquarum rerum, sicut princeps civitatis in rebus civilibus, dux autem exercitus in rebus bellicis, magister autem in disciplinis, et simile est in aliis. Et inde est quod omnes tales personae patres appellantur, propter similitudinem curae (Tomás de Aquino, Summa Theologiae II-II, q.102, a.1 in c). santuario familiar. Por último, corresponde a los hijos ser dóciles a sus padres durante la educación, y ser agradecidos por la educación recibida.

¿Por qué, sin embargo, hay hijos que rechazan la educación paterna? ¿Por qué hay hijos que se van de la casa del padre a dilapidar su herencia? Porque se consideran autosuficientes. Se creen maestros de sí mismos. Se repite en el seno de la familia aquella antigua tentación de la serpiente a Adán, acerca de la que nos ilumina de nuevo el Aquinate:

El primer hombre pecó sobre todo al desear la semejanza con Dios en cuanto al conocimiento del bien y del mal, como la serpiente le sugirió, es decir, el poder determinar, con su propia naturaleza, lo que era bueno o malo que fuera a sucederles ${ }^{4}$.

El maestro de sí mismo es el que pretende determinar su propio camino, según hemos visto. Es el que rechaza la mirada del padre o del maestro para mirarse sólo a sí mismo, como Narciso. Esto es lo que hizo Adán cuando rechazó el mandato de Dios Padre, esto es lo que hizo el hijo pródigo cuando rechazó seguir en la casa de su padre, esto es lo que hace el hijo que rechaza la educación paterna. $Y$ es que este rechazo no puede explicarse en su significado último sino a la luz del pecado original.

Tras el rechazo de la autoridad educativa de los padres comienza una andadura fuera de la casa paterna, si no física, al menos espiritual. Sigue entonces el rechazo a la autoridad de los maestros, de los gobernantes, de los pastores de la Iglesia... Hasta que se llega finalmente a rechazar la autoridad de Dios, que es el principio de

4 Sed primus homo peccavit principaliter appetendo similitudinem Dei quantum ad scientiam boni et mali, sicut serpens ei suggessit, ut scilicet per virtutem propriae naturae determinaret sibi quid esset bonum et quid malum ad agendum; vel etiam ut per seipsum praecognosceret quid sibi boni vel mali esset futurum (Tomás de Aquino, Summa Theologiae II-II, q.163, a.2 in c). 
toda autoridad. Muerte del padre, muerte del maestro, muerte de Dios.

Una confirmación de este diagnóstico la encontramos en aquella profética encíclica del Papa Pío XI, Divini illius magistri, escrita en el origen de esta crisis:

Es erróneo -enseña el Pontífice- todo método de educación que se funde, total o parcialmente, en la negación o en el olvido del pecado original y de la gracia, y por consiguiente, sobre las solas fuerzas de la naturaleza humana. A esta categoría pertenecen, en general, todos esos sistemas pedagógicos modernos que, con diversos nombres, sitúan el fundamento de la educación en una pretendida autonomía y libertad ilimitada del niño o en la supresión de toda autoridad del educador, atribuyendo al niño un primado exclusivo en la iniciativa independiente de toda ley superior, natural y divina, en la obra de la educación (PÍO XI, Divini Illius Magistri, 45).

El hijo que ha abandonado la educación paterna disfrutará, seguramente, de gozos inmediatos, dilapidando en ellos su herencia. Pero finalmente, el hijo caminará desorientado; sentirá el hambre de la pobreza interior; experimentará la soledad del que ha perdido la mirada amorosa de su padre, será, en palabras de Canals: "el hombre a quien nadie miró". El resultado ya lo conocemos: la tristeza que apesadumbra, y sus consecuencias de huida y resentimiento.

Hasta ahora hemos diagnosticado la enfermedad y sus causas. ¿Pero podemos ponerle remedio? ¿Es posible salir de la crisis despersonalizadora? Voy a tratar de referirme a estas propuestas educativas a continuación, en la tercera parte de mi intervención.

La respuesta está en volver a la persona. Pero, ¿qué significa "volver a la persona"? Porque ésta puede ser una expresión agradable a los oídos, pero vacía de contenido. "Volver a la persona", volver a mirar al hombre como alguien, no significa quedarse en una mera consideración fenoménica del rostro humano, de sus caracteres diferenciales, de su lenguaje, de su cultura, de su obrar. Significa, por el contrario, contemplar metafísicamente su ser subsistente y distinto en una naturaleza racional, por el que es "perfectissimum in tota natura". Significa contemplar metafísicamente el orden del universo, cuyo fin intrínseco es materialiter ese mismo orden en su conjunto, pero formaliter es la creatura racional, que por esa racionalidad es en cierto modo todo el universo, quodammodo omnia, y por ello es capaz del Sumo Bien, capax Dei:

El universo es más perfecto en bondad que la criatura intelectual de un modo extensivo y difusivo. Pero en el aspecto intensivo y colectivo, la semejanza de la perfección divina se encuentra más en la criatura intelectual, que es capaz del sumo bien ${ }^{5}$.

Significa contemplar metafísicamente la difusión comunicativa de la perfección personal, no del actus essendi, que es incomunicable, sino de la propia naturaleza en la persona engendrada, ya materialiter en la generación física humana, ya formaliter en la generación intelectual por medio de la palabra.

Y así esta generación es la que revela más plenamente el rostro ontológico de la persona. No debe entenderse en esto que la paternidad y la filiación que resultan de la generación sean el constitutivo formal de la persona, sino que el subsistir en la naturaleza racional tiende en su perfección, ex plenitudine, y no en su indigencia, a ser difusivo de sí mismo según la propia naturaleza. Esta generación es por la que dice Santo Tomás que el hombre es más semejante a Dios que incluso el án-

5 Universum est perfectius in bonitate quam intellectualis creatura extensive et diffusive. Sed intensive et collective similitudo divinae perfectionis magis invenitur in intellectuali creatura, quae est capax summi boni (Tomás de Aquino, Summa Theologiae I, q.93, a.2 ad 3). 
gel: "homo est de homine sicut Deus de Deo" (Summa Theologiae I, q.93, a.3 in c). Generación humana en la que la física se ordena por naturaleza a la intelectual que la completa y perfecciona, esto es, a la educación de los hijos. Educación que es, por ello, una segunda generación: Sicut pater te genuit corporaliter, etiam magister genuit te spiritualiter (Aquino, Sermo Puer lesus pars 3).

Tal contemplación metafísica de la persona puede concretarse en propuesta educativa de dos maneras. La primera consiste en la recuperación de la metafísica de la persona de Santo Tomás de Aquino, quien "por haber venerado en gran manera los antiguos Doctores sagrados, obtuvo de algún modo la inteligencia de todos" (LEÓN XIII, Aeterni Patris). Recuperación cuyo lugar natural no es otro que la Universidad, principalmente en las Facultades de Filosofía y de Teología que pertenecen esencialmente a toda Universidad Católica y desde las que, como determina la Constitución Ex Corde Ecclesiae, iluminan y ordenan todos los otros estudios:

Guiados por las aportaciones específicas de la filosofía y de la teología, los estudios universitarios se esforzarán constantemente en determinar el lugar correspondiente y el sentido de cada una de las diversas disciplinas en el marco de una visión de la persona humana y del mundo iluminada por el Evangelio y, consiguientemente, por la fe en Cristo-Logos, como centro de la creación y de la historia (Juan Pablo II, Ex Corde Ecclesiae, 16).

La segunda consiste en la reordenación de toda la vida social a partir de la educación paterna. Se entiende ahora mejor por qué la raíz misma de la despersonalización es la pérdida de la autoridad paterna, de la mirada del padre.

Y como es el hijo el que la rechaza, parece que es a éste a quien hay que dirigir principalmente los remedios. Pero esto es un error, pues a quien hay que sanar primero es al educador. Santo Tomás lo explica claramente en su toma de posesión de la cátedra en París: así como de las cumbres de los montes vienen las aguas que riegan los valles, así de los maestros viene la enseñanza que riega las almas de sus alumnos.

Lo primero que deben recuperar los padres y los maestros es la percepción nítida del fin de la educación. ¿Y cuál es? Santo Tomás nos lo enseña en un texto fundamental, que citó literalmente el Papa Pío XI en aquella encíclica: “La naturaleza no pretende solamente la generación de la prole, sino también su conducción y promoción hasta el estado perfecto del hombre en cuanto hombre, que es el estado de virtud" 6 . La virtud, ése es el fin de la educación. Es decir, la adquisición de hábitos que ayuden a obrar bien y a caminar con paso firme hacia la felicidad. iQué necesitada está la educación actual de volver a oír hablar de virtudes! Prudencia, justicia, piedad, religión, fortaleza, magnanimidad, paciencia, templanza, castidad, humildad. Y, cómo no, las virtudes divinas: fe, esperanza y caridad. iVirtudes arraigadas en el alma como una segunda naturaleza, y no valores abstractos!

Pero no basta con vislumbrar el fin. Hay que recuperar la esperanza de alcanzarlo. Cabe esperar, en primer lugar, una respuesta del educando desde sí mismo. La naturaleza, en efecto, no quedó radicalmente corrompida por el pecado original. Además, esta respuesta puede verse favorecida por la semejanza que hay entre padre e hijo, entre maestro y alumno. En efecto, esta semejanza mue-

6 Matrimonium est naturale, quia ratio naturalis ad ipsum inclinat dupliciter. Primo quantum ad principalem ejus finem, qui est bonum prolis: non enim intendit natura solum generationem ejus, sed traductionem, et promotionem usque ad perfectum statum hominis, inquantum homo est, qui est virtutis status (Tomás de Aquino, In IV Sent. d.26, q.1, a.1 in c.) (Pío XI, Divini Illius Magistri, 17). 
ve al educando a confiar, consiguiendo de un modo connatural su respuesta; de ahí que diga Aristóteles que "creer es algo necesario a quien aprende" (Las refutaciones Sofísticas, 2, 165b3). En consecuencia, los padres y maestros deben saber ver y cultivar en sus hijos y alumnos la imagen de ellos mismos. Es natural que el discípulo se asemeje al maestro como el hijo se asemeja al padre, y eso es lo que constituye la escuela y la familia.

La fecundidad de la semejanza pone además de manifiesto la importancia educativa de la amistad. Dice Aristóteles que "lo que podemos por los amigos lo podemos por nosotros mismos" (Ética Nicomáquea, III, c.3, 1112b 27). Por ello, los padres deben saber potenciar las amistades de los hijos como prolongación de sus propias amistades; los maestros deben saber potenciar el ambiente amigable y cordial en la escuela, como prolongación del ambiente familiar. Una particular fuerza educativa se da en comunidades de familias, en las que niños, jóvenes y adultos se ven acompañados por otros semejantes.

Pero la confianza y las amistades naturales no son suficientes. Aquel rechazo radical de la educación paterna exige mucho más que las propias fuerzas del hijo. Sólo la gracia puede devolverlos a la casa paterna. $Y$ así deben esperarlo los padres, pidiéndolo insistentemente, como hiciera Santa Mónica. No buscarán entonces los padres su imagen en los hijos, sino la imagen de Cristo, como afirma San Pablo: "hasta que lleguemos al estado de hombre perfecto, a la madurez de la plenitud de Cristo" (Ef 4, 13). Además, la gracia no destruye la naturaleza sino que la perfecciona; por ello, la gracia perfeccionará también todo el orden natural de la educación. iQué triste es ver una escuela católica en la que la fe y la gracia hayan quedado recluidas a la capilla o a la clase de religión! Como si su lema fuera aquel etsi Deus non daretur. iEn modo alguno! iLa escuela católica en su integridad debe hacer presente a Cristo!

Esta percepción y esperanza del fin conseguirá que los padres y maestros sean los primeros en recuperar la conciencia de su propia autoridad. Tienen una admirable vocación: educar a sus hijos y alumnos. Parafraseando a San León Magno podríamos decirles: "iReconoce, padre y maestro, tu dignidad!". Sólo con esa convicción podrá uno hablar con autoridad. Esto no lo dan los libros de pedagogía, ni las reuniones, ni las nuevas tecnologías.

Pero también hay que ser consciente de que es una vocación recibida. Un padre antes fue hijo, y recibió una educación; un maestro antes fue alumno, y recibió una enseñanza. Se tiene autoridad, y no mera potestad cuando uno se siente en el seno de una tradición. La semejanza que uno ve en sus hijos y alumnos, debe reconocerla primero en sus propios padres y maestros. En una época en que se siente aversión a asemejarse a padres y maestros, hay que recordar aquella expresión popular española: "Quien a los suyos se parece, honra merece". iQué gran lema para todo padre y todo maestro!

Quien se sabe heredero de una tradición y espera en el fruto de su educación, sentirá de nuevo el gozo por educar. Más aún, hará despertar de forma connatural ese gozo en su hijo o alumno. Y si éste ha abandonado ya la casa paterna, que le pregunte a Cristo, nuestro Maestro, quien la dará la respuesta en la parábola. Allí le enseñará que cuando vea de nuevo a su hijo caminando triste, no será el resentimiento, sino su mirada misericordiosa de padre, la que le hará experimentar de nuevo que es verdaderamente hijo. 


\section{REFERENCIAS}

Aquino, T. (1947). (Benziger Bros, trad.). Summa Theologiae l, q.29, a.3 in c.

Aquino, T. (1947). (Benziger Bros, trad.). Summa Theologiae II-II, q.35, a.1 in c.

Aquino, T. (1947). (Benziger Bros, trad.). Summa Theologiae I, II-II, q.35, a.4 ad 3.

Aquino, T. (2002). De Veritate q.11, a.2. ). Universidad de Navarra: España.

Aristóteles. (1985). Ética Nicomáquea, III, c.3, 1112b 27

Aristóteles. (1985). Ética Nicomáquea, VIII, c.5, 1157b15.

Aristóteles. (1974). Política, II, c.5.

Aristóteles, (1982) Las refutaciones Sofísticas, 2, 165b3
Canals, F. (1976) Teoría y praxis en la perspectiva de la dignidad del ser personal. En: Espíritu XXV, p.121-128.

Canals, F. (2004). La pereza activa. En: E-aquinas II, p.2-12.

Chantraine, P. (1984). Dictionnaire étymologique de la langue grecque. Histoire des mots, Vol. II. Paris: Éds. Klincksiek.

Juan Pablo II. (1990). Ex Corde Ecclesiae, (16).

León XIII. (1879). Aeterni Patris.

Martínez, E. (2010). El término "prósopon" en el encuentro entre fe y razón. En: Espíritu LIX, p.173-193.

Millan-Puelles. (1989). La formación de la personalidad humana, $7^{\mathrm{a}}$ ed., Madrid: Ediciones Rialp S.A.

Sheller, M. (1993). El resentimiento en la moral. Madrid: Caparrós Editores. 